\title{
A Survey of Dietary and Exercise Habits and Perceived Barriers to Following a Healthy Lifestyle in a College Population
}

\author{
Kathryn Silliman, Kathleen Rodas-Fortier, Michelle Neyman \\ California State University, Chico
}

\begin{abstract}
The authors assessed the diet and exercise habits and perceived barriers to following a healthy lifestyle of 471 college students. Sixty percent of the participants were female and 31\% had BMIs $>25$. Breakfast was the most commonly missed meal and $63 \%$ of students snacked one to two times per day. Fifty-eight percent of participants ate vegetables and $64 \%$ ate whole or canned fruit less than once per day. Men consumed more soda and alcohol and used higher fat dairy, ate more meat, and ate fewer vegetables and fruits than women. Over half of the subjects rated their diet as poor or fair with "lack of time" listed as the number one barrier to eating well. Men exercised more frequently and at greater intensity than women and were more confident with their body image. The most common barrier to exercise was "lack of time.” The results of this study have implications for the design of general and specific diet and physical activity interventions among college students.
\end{abstract}

(C) 2004 Californian Journal of Health Promotion. All rights reserved.

Keywords: college students, diet, exercise, barriers

\section{Introduction}

Diet related diseases including cardiovascular disease, cancer, and stroke are consistently among the top three leading causes of death (American Cancer Society, 2000). A new report, issued by the Institute of Medicine (IOM) of the National Academy of Sciences, suggests that to save the most lives from chronic disease, policy makers, health care providers and researchers should focus their efforts on helping people to stop smoking; maintain a healthy weight and diet; exercise regularly; and drink alcohol at low to moderate levels (American Cancer Society, 2003). Most college students may not achieve the nutrition and exercise guidelines designed to reduce the risk of chronic disease, typically consuming diets high in fat, sodium, and sugar and low in fruits and vegetables (Anding et al., 2001; Dinger \& Waigandt, 1997; Grace, 1997; Hiza \& Gerrior, 2002; TLHS, 2000). These poor eating habits may result from frequent snacking, excess dieting, and consumption of calorie dense but nutrient poor snacks and meals, such as those provided by fast food restaurants (Georgiou et al., 1997). In addition, despite the recognized benefit of exercise, surveys of college students' health habits indicate that only 35\% have a regular schedule of physical activity and that a slightly higher proportion of men (40\%) than women (32\%) regularly exercise (Pinto et al., 1998). However, college students are at a time and place in their lives where their behavior is conducive to change. In fact, the students' social role of learner is largely defined by a readiness to change (NIH, 1998). Therefore, college campuses serve as crucial settings to overcome perceived barriers to healthy diet and exercise habits, and implement effective interventions (Wallace et al., 2000). Ideally, if college students make positive changes in exercise and dietary habits, these changes could persist into adult years. The purpose of this survey was to assess the diet and exercise habits and perceived barriers to following a healthy lifestyle of college students and to determine if differences exist by gender. The results may have implications for the design of effective general and gender specific interventions for college students. 


\section{Methods}

\section{Participants}

A total of 471 college students enrolled in the study during the spring semester 2002. Participants were recruited using a stratified random sample of classes from upper and lower division general education classes. Final class selection was dependent on obtaining instructor permission to enter classes. A proportionate number of students from lower and upper division classes were selected. The study protocol and survey instrument were approved by the university's institutional review board for the protection of human subjects. Characteristics of the 471 participants are shown in Table 1.

Table 1

Characteristics of the Participants

\begin{tabular}{|c|r|r|}
\hline Characteristics & $\begin{array}{c}\text { \# of } \\
\text { Participants }\end{array}$ & $\begin{array}{c}\text { \% of } \\
\text { Participants }\end{array}$ \\
\hline Gender & 199 & 43 \\
\hline Male & 264 & 57 \\
\hline Female & & 60 \\
\hline Age (years) & 281 & 32 \\
\hline $18-21$ & 149 & 8 \\
\hline $22-25$ & 39 & 21 \\
\hline $26+$ & & 20 \\
\hline Class Standing & 98 & 31 \\
\hline Freshman & 93 & 27 \\
\hline Sophomore & 144 & 2 \\
\hline Junior & 127 & 69 \\
\hline Senior & 8 & 25 \\
\hline Graduate & & 6 \\
\hline Body Mass Index $\left(\mathrm{kg} / \mathrm{m}^{2}\right)$ & 323 & 118 \\
\hline$<25$ & 25 & \\
\hline $25-29.9$ & & \\
\hline$>30$ & & \\
\hline
\end{tabular}

\section{Design}

All participants were asked to complete a survey designed to assess the dietary and exercise habits and perceived barriers to following a healthy lifestyle of college students. The current survey was adapted from a University of North Florida's survey of diet and exercise of freshman (Rodriguez, 1999). The survey had 38 questions and was divided into three sections. The first section (six questions) asked for anthropometric and demographic data. The second section (20 questions) asked participants about their current dietary habits and perceived barriers to eating a healthy diet. The third section (nine questions) asked participants about their current physical activity patterns, perceived body image and perceived barriers to an active life. The survey took approximately 15 minutes to complete.

\section{Statistical Analyses}

We used the SPSS package (LEAD Technologies, Inc.) for Windows, release 11.0, to analyze the data. Frequencies were used as descriptors of the student population. Chi-square $\left(\chi^{2}\right)$ statistics were used to examine differences in frequencies of responses to questions on dietary and exercise habits and perceived barriers to following a healthy lifestyle by gender. 


\section{Results}

Approximately $60 \%$ of the participants were female and most were aged 18-21 years (Table 1). There were very few graduate students represented in this sample. Thirty-one percent of the population had a body-mass-index (BMI) greater than 25 based on self-reported height and weight data, indicating a high percentage of overweight (BMI 25 - 29.9) and obese (BMI > 30) individuals in such a young population. Forty percent of men compared with $20 \%$ of women had a BMI greater than 25 . One question on the survey asked participants if they had lost, gained or had no change in weight in the last few years. Of the 414 participants who responded to this question, $46 \%$ stated they had gained weight, $30 \%$ had no change in weight, and $24 \%$ had lost weight. Of those that had gained weight, the average \pm SD gain was $12 \pm$ 10 pounds (range: $2-100$ pounds).

\section{Dietary Habits and Perceived Barriers to Healthy Eating}

Students were asked how often they ate meals. Breakfast is the most commonly missed meal. Responses (\% of participants) are as follows: Breakfast- never (8), seldom (25), sometimes (21), usually (24), always (23); Lunch- never (1), seldom (2), sometimes (16), usually (44), always (37); Dinner- never (0), seldom (1), sometimes (4), usually (30), always (65). There are no differences between male and female participants.

Students were asked about frequency of snacking and consumption of soda and alcohol. Most students (63\%) are inclined to snack one to two times per day. There are gender differences in the reasons for snacking, types of snacks, and the frequency of soda and alcohol consumption, see Table 2. While "boredom" is the most frequently cited reason for snacking, men state "partying" as a reason for snacking more frequently than women and women state "emotional" more frequently than men. Most students snack on chips, crackers, or nuts; but men snack on fast foods more and on ice cream, cookies and candy less frequently than women. Men consume larger quantities of both soda and alcoholic beverages than women. Men also use higher fat dairy products, eat more lean and high fat meats, and eat fewer vegetables and canned and whole fruits than women (see Table 3). Fifty-eight percent of participants state they eat vegetables less than once per day and $64 \%$ eat whole or canned fruit less than once per day.

When asked to rate the "healthiness" of their eating habits, $51 \%$ of participants state "poor" or "fair." When asked to state the reasons for poor eating habits, $40 \%$ state "lack of time," $22 \%$ state "lack of money," $15 \%$ state "taste preferences” and $24 \%$ state other reasons. Some of the other reasons stated include "no motivation” ( $\mathrm{n}=21)$, “convenience” $(\mathrm{n}=20)$, and "dine at student cafeteria" $(\mathrm{n}=17)$. Fortytwo percent of women state "lack of time" compared with $36 \%$ of men, whereas $3 \%$ of women state "don't care" compared with $11 \%$ of men $\left(\chi^{2}, \mathrm{p}<0.05\right)$.

\section{Exercise Habits, Body Image and Perceived Barriers to Exercise}

Eighty-four percent of participants stated they currently exercise and the same percentage state they exercised prior to attending college, however, $42 \%$ state they exercise less since attending college. Men exercise more frequently and at a greater intensity level than women, see Table 4. In regard to type of exercise, women do more aerobics and less strength-training and partake in fewer competitive sports than men. Men appear to be more confident with their body image. The most commonly cited reason why the participants exercised is "health" ( $\mathrm{n}=$ 251). There are other stated differences between men and women, see Table 5. Women exercise for reasons of weight and stress reduction and men exercise for enjoyment and gains in muscle and strength. The most commonly cited barriers to exercise are "lack of time" ( $n=171)$, "lack of motivation" ( $\mathrm{n}=103)$ and "lack of willpower" $(n=45)$. There are no differences in barriers to exercise by gender. 
Table 2

Questions about Snacking, Soda, and Alcohol by Gender

\begin{tabular}{|c|c|c|c|}
\hline Question & $\begin{array}{c}\text { Female } \\
(\%)\end{array}$ & $\begin{array}{c}\text { Male } \\
(\%)\end{array}$ & $\begin{array}{l}\text { p Value } \\
\left(\chi^{2}\right)\end{array}$ \\
\hline \multicolumn{4}{|c|}{$\begin{array}{l}\text { Are you more inclined to snack in any of the following } \\
\text { situations? }\end{array}$} \\
\hline Studying & 23 & 20 & \\
\hline Partying & 9 & 20 & \\
\hline Bored & 51 & 43 & .001 \\
\hline Emotional & 9 & 2 & \\
\hline Other & 9 & 160 & \\
\hline \multicolumn{4}{|c|}{ What types of food do you normally snack on? } \\
\hline Chips, crackers, or nuts & 57 & 54 & \\
\hline Ice cream, cookies, candy & 18 & 10 & .024 \\
\hline Fast foods (e.g. pizza, fries) & 8 & 14 & \\
\hline Other & 18 & 22 & \\
\hline \multicolumn{4}{|c|}{$\begin{array}{l}\text { How often do you drink regular soda or other sugared } \\
\text { beverages ( } 1 \text { cup = } 1 \text { serving)? }\end{array}$} \\
\hline Never & 17 & 11 & \\
\hline Occasionally & 35 & 30 & \\
\hline A few times per week & 22 & 21 & \\
\hline One to two times per day & 17 & 24 & .045 \\
\hline Two to three times per day & 7 & 9 & \\
\hline More than 4 times per day & 2 & 5 & \\
\hline \multicolumn{4}{|c|}{$\begin{array}{l}\text { What is the average number of alcoholic drinks (a drink is a } \\
\text { can/bottle of beer, glass of wine, wine cooler, shot glass of } \\
\text { liquor, or a mixed drink) you usually consume in a week? }\end{array}$} \\
\hline $0-7$ & 74 & 51 & \\
\hline $8-14$ & 15 & 24 & .001 \\
\hline $15-21$ & 9 & 10 & \\
\hline 22 or more & 2 & 15 & \\
\hline
\end{tabular}

Table 3

Response to Dietary Questions by Gender

\begin{tabular}{|c|c|c|c|}
\hline $\begin{array}{l}\text { Question } \\
\end{array}$ & Female (\%) & Male (\%) & p Value $\left(\chi^{2}\right)$ \\
\hline \multicolumn{4}{|l|}{ What type of milk/yogurt/ do you consume? } \\
\hline I don't consume cow's milk/yogurt & 10 & 14 & \\
\hline I consume only skim or $1 \%$ milk/yogurt & 52 & 32 & .001 \\
\hline $\begin{array}{l}\text { I usually consume skim or } 1 \% \text { milk/yogurt but use others } \\
\text { occasionally }\end{array}$ & 18 & 13 & \\
\hline I usually consume $2 \%$ or whole milk/yogurt & 20 & 42 & \\
\hline \multicolumn{4}{|l|}{$\begin{array}{l}\text { How often do you eat lean meat (lean beef, chicken, turkey, } \\
\text { fish)? }\end{array}$} \\
\hline I never eat any of these meats & 5 & 1 & \\
\hline I eat them about once per week or less & 25 & 24 & .041 \\
\hline I eat them about 2 to 4 times per week & 53 & 53 & \\
\hline I eat them more than 4 times per week & 16 & 22 & \\
\hline
\end{tabular}




\begin{tabular}{|c|c|c|c|}
\hline Question & Female (\%) & Male (\%) & p Value $\left(\chi^{2}\right)$ \\
\hline \multicolumn{4}{|c|}{$\begin{array}{l}\text { How often do you eat these meats: regular hamburger, } \\
\text { bologna, salami, hot dogs, corned beef, spareribs, sausage, } \\
\text { bacon, pastrami, or liver? }\end{array}$} \\
\hline I never eat any of these meats & 26 & 6 & \\
\hline I eat them about once per week or less & 53 & 38 & .001 \\
\hline I eat them about 2 to 4 times per week & 18 & 39 & \\
\hline I eat them more than 4 times per week & 3 & 18 & \\
\hline \multicolumn{4}{|c|}{$\begin{array}{l}\text { How often do you eat vegetables? }(1 / 2 \text { cup cooked/ } 1 \text { cup } \\
\text { raw = } 1 \text { serving) }\end{array}$} \\
\hline I eat vegetables once per week or less & 11 & 18 & \\
\hline I eat vegetables 2 to 6 times per week & 41 & 34 & \\
\hline I eat vegetables 1 time per day & 34 & 32 & .002 \\
\hline I eat vegetables 2 to 3 times per day & 13 & 15 & \\
\hline I eat vegetables more than 4 times per day & 10 & 20 & \\
\hline \multicolumn{4}{|c|}{$\begin{array}{l}\text { How often do you eat whole or canned fruit? (1 piece OR } 1 / 2 \\
\text { cup canned = } 1 \text { serving) }\end{array}$} \\
\hline I eat fruit once per week or less & 19 & 35 & \\
\hline I eat fruit 2 to 6 times per week & 39 & 37 & \\
\hline I eat fruit 1 time per day & 14 & 16 & .001 \\
\hline I eat fruit 2 to 3 times per day & 25 & 11 & \\
\hline I eat fruit more than 4 times per day & 3 & 2 & \\
\hline
\end{tabular}

Table 4

Response to Exercise/Body Image Questions by Gender

\begin{tabular}{|c|c|c|c|}
\hline Question & Female (\%) & Male (\%) & p Value $\left(\chi^{2}\right)$ \\
\hline \multicolumn{4}{|l|}{ How often do you exercise? } \\
\hline I exercise 0 -2 times per week & 38 & 32 & \\
\hline I exercise 3-4 times per week & 45 & 37 & .003 \\
\hline I exercise 5 or more times per week & 17 & 30 & \\
\hline \multicolumn{4}{|l|}{ At what level of intensity do you exercise? } \\
\hline Light & 8 & 7 & \\
\hline Moderate & 41 & 22 & .001 \\
\hline Heavy & 51 & 71 & \\
\hline \multicolumn{4}{|l|}{ What type of exercise do you usually do? } \\
\hline Cross-training & 8 & 7 & \\
\hline Aerobic & 40 & 11 & \\
\hline Strength-training & 2 & 19 & \\
\hline Competitive sports & 6 & 16 & .001 \\
\hline Combination & 42 & 47 & \\
\hline Other & 2 & 1 & \\
\hline \multicolumn{4}{|l|}{ How do you feel about your body? } \\
\hline I feel confident with how my body looks & 16 & 38 & \\
\hline I feel somewhat confident with how my body looks & 61 & 51 & .001 \\
\hline I don’t feel confident with how my body looks & 23 & 11 & \\
\hline
\end{tabular}


Table 5

Reason for Exercising by Gender

\begin{tabular}{|l|r|r|r|}
\hline \multicolumn{1}{|c|}{ Stated Reason } & Female (\%) & Male (\%) & p Value $\left.\mathbf{\chi}^{\mathbf{2}}\right)$ \\
\hline Weight Loss/ Maintain Weight & 56 & 25 & .001 \\
\hline Stress Relief & 47 & 32 & .001 \\
\hline Enjoyment & 28 & 46 & .001 \\
\hline Gain Muscle/Strength/Fitness & 8 & 16 & .022 \\
\hline Other & 22 & 30 & .051 \\
\hline
\end{tabular}

\section{Discussion}

The purpose of this survey was to assess the diet and exercise habits and perceived barriers to following a healthy lifestyle of college students and to determine if differences exist by gender. The survey population is young; most students are 21 years of age or younger, and there are a fairly even distribution of students by class standing. Twenty-five percent of students have a body mass index (BMI) placing them in the overweight category and $6 \%$ are classified as obese. In close agreement with the current survey, Lowry et al. (2000) report that $35 \%$ of college students are overweight or obese based on the 1995 National College Health Risk Behavior Survey. In contrast, Haberman and Luffey (1998), in a population of 302 college students, report that $8 \%$ are overweight. Female students in this survey population have a similar incidence of overweight (20\%) as that reported by Anding et al. (2001) in a small population of 60 female students (25\%). While $40 \%$ of men in this survey have a BMI greater than $25,19 \%$ of these men report that they strength-train and $41 \%$ report they do a combination of exercise. Many of these men may have a greater proportion of lean body mass. Self-reported height and weight data must be viewed with caution as Jacobson and DeBock (2001) recently reported that college men underestimate height and college women underestimate weight.

Many college students have poor nutritional habits (Georgiou et al., 1997). Most do not meet the minimum recommended intake of dietary fiber, fruits, and vegetables; and exceed recommended intakes of total fat and saturated fat, sugar, and sodium (Anding et al., 2001;
Grace, 1997; Hiza \& Gerrior, 2002; TLHS, 2000). Thirty-three percent of this survey population report they consume breakfast "never" or "seldom." Hertsler and Frary (1989) studied food behavior among 212 college students where $43 \%$ report skipping breakfast more than half the time. Eighty percent also indicate that they snack one to three times per day while $4 \%$ note four or more times per day. In the present survey, $63 \%$ are inclined to snack one to two times per day, $26 \%$ three to four times per day and $5 \%$ four or more times per day. "Boredom" was the most frequently cited reason for snacking. The present survey also found gender differences in types of snack foods and additional reasons for snacking. Men state "partying" as a reason for snacking more frequently than women and women state "emotional" more frequently than men. While most students snack on chips, crackers, or nuts; men snack on fast foods more and on ice cream, cookies and candy less frequently than women. Twenty-six percent of women and 38\% of men in the current study report drinking regular soda or other sugared beverages one or more times per day. While the authors defined a serving as equaling one cup, it is clear that most students purchase much larger sodas; the standard serving sold on campus is 20 ounces. Larger portion sizes leading to significantly increased caloric intake are implicated in the national obesity epidemic (Young \& Nestle, 2002). Soda may be just one source of excess calories in the college students' diet. A recent study (Lang, 2003) suggests that the "freshman 15," the gain of 15 pounds of weight by freshman during the first year of college, may be a real phenomenon fostered by "all you can eat" dining facilities, 
evening snacks, consumption of junk food, and dieting. It is reported that nation wide bingedrinking among college students exceeds 40\% (Grace, 1997). Men are heavier drinkers than women in the present survey where $15 \%$ state they usually drink 22 or more drinks per week. Wechsler et al. (Wechsler \& Isaac, 1992; Wechsler et al., 2000) also confirm that male students drink more frequently than female students.

Only a small percentage of college students are consuming the recommended number of servings for fruits, vegetables, and dairy (Hiza \& Gerrior, 2002; Georgiou et al., 1997). In the present survey, $58 \%$ and $64 \%$ of the participants state they consume vegetables or whole or canned fruit less than once per day, respectively. This agrees with the $51 \%$ of participants who rate the "healthiness" of their eating habits as poor or fair. Dinger and Waigandt (1997) surveyed over 2,600 college students and found that $40 \%$ had not eaten any fruit in the previous 24 hours and 55\% had not eaten green salad or cooked vegetables. According to a study by Debate et al. (2001), in a population of 630 college students, only $18 \%$ consume five servings per day of fruits and vegetables, 7\% consume six or more grain products, and 53\% consume two or more dairy products. An earlier study by Melby et al. (1986) reported that 69\% of college students do no eat any fruit once a day and $48 \%$ eat vegetables less than once a day. These findings are cause for concern because there is ample data suggesting that fruit and vegetable consumption may be protective against most cancers and cardiovascular disease. The decreased risk of chronic disease associated with a plant-based diet may be due to substances in fruit and vegetables such as antioxidants, folate, fiber, potassium, flavonoids and numerous other phytochemicals (Hyson, 2002; Van Duyn \& Pivonka, 2000).

The most common barrier cited to eating well is "lack of time." Other common reasons are "lack of money" and "taste preferences." LopezAzpiazu et al. (1999) examined perceived barriers of healthy eating among 1009 Spanish adults, over the age of 15 years, and found the common barriers were "irregular work hours," "willpower," and "unappealing food." Lappalainen et al. (1997) reported that "irregular work hours," "giving up foods I like," and "willpower" are the most common barriers to trying to eat healthier in a large study with over 14,000 European adults, 15 years of age and older. The present survey noted some differences in barriers between men and women. More women state "lack to time," while three times as many men state "don’t care."

The steepest decline in physical activity occurs during adolescence and young adulthood (Allison et al, 1999; Grace, 1997; Leslie et al., 1999). Pinto and Marcus (1995) report that 46\% of young adults on college campuses are inactive or active irregularly and only about 35\% have a regular schedule of physical activity. This is similar to results of Dinger and Waugandt (1997) who found that 30\% of college students did not engage in moderate physical activity the previous week and only 45\% report participating in vigorous physical activity. Haberman and Luffey (1998) also state that only 39\% of 302 college students exercise enough to meet the Healthy People 2000 goal for activity. In contrast, in this particular population of college students, $84 \%$ state they currently exercise. However, it should be noted that exercise (frequency or intensity) was not defined. Despite this high reported rate of activity, 42\% state they exercise less since attending college. Leslie et al. (1999) found that about $70 \%$ of a population of over 2,700 college students report less activity at college. Men exercise more frequently and at a greater intensity level than women and men select strength-training and competitive sports more than women. Women select aerobics more than men. These gender differences also are reported by Leslie et al. (1999) and Pinto and Marcus (1995).

The main reason participants' exercised in this survey was for "health." Among other stated reasons, women exercise because of weight and stress reduction and men exercise for enjoyment and gains in muscle and strength. Similarly, Myers and Roth (1997) found that college women exercise for its psychological and body image benefits and Leslie et al. (1999) found that men are motivated to exercise for muscle 
gain. Not surprisingly, $38 \%$ of male students felt confident with how their body looked compared with only $16 \%$ of female students. In a survey of 630 college students, almost $50 \%$ of white and $25 \%$ of African American females, who fell within an acceptable BMI range (19-25), desire to be in the underweight range. These results suggest that college-aged women are dissatisfied with their current body size (Nutrition Research Newsletter, 2002). Adolescents state that "time," "lack of interest/other interests," "not in the mood," and "lack of energy" as common barriers to exercise (Allison et al., 1999; Tappe et al., 1989) The present survey found that the most commonly cited barriers to exercise were "lack of time," "lack of motivation," and "lack of willpower."
The current study suggests that there is much room for improvement in the diet and exercise habits of this college-aged population. Gender specific interventions may be warranted given the evidence that different barriers to healthy eating and exercise exist between male and female students. In addition, with "lack of time" the most frequently mentioned barrier to eating a healthy diet and engaging in regular exercise, the challenge becomes developing and evaluating interventions that are not only appealing and motivating to this demographic, but also will fit within their time constraints. Health advocates should take advantage of the opportunity that exists for building a foundation of lifelong healthy diet and exercise habits among college students thereby reducing their future risk of chronic disease.

\section{References}

Allison, K., Dwyer, J., Makin, S. (1999). Perceived barriers to physical activity among high school students. Preventive Medicine, 28, 608-615.

American Cancer Society. (2003). American Cancer Society and Institute of Medicine: 60,000 cancer deaths and 100,000 new cases avoidable annually. Healthier lifestyles and recommended early detection tests can dramatically reduce cancer risks. Press Release, June 30, 2003.

American Cancer Society. (2000). California cancer facts and figures (2001). Oakland, CA: California Division and Public Health Institute, California Cancer Registry.

Anding, J. D., Suminiski, R. R., Boss, L. (2001). Dietary intake, body mass index, exercise, and alcohol: are college women following the dietary guidelines? Journal of American College Health, 49, 167-171.

Debate, R. D., Topping, M., Sargent, R. G. (2001). Racial and gender differences in weight status and dietary practices among college students. Adolescence, 36, 819-833.

Dinger, M., and Waigandt, A. (1997). Dietary intake and physical activity behaviors of male and female college students. American Journal of Health Promotion, 11, 360-362.

Georgiou, C., Betts, N., Hoerr, S., Keim, K., Peters, P.K., Stewart, B., Voichick, J. (1997). Among young adults, college students and graduates practiced more healthful habits and made more healthful food choices than did non-students. Journal of the American Dietetic Association, 7, 754-759.

Grace, T. W. (1997). Health problems of college students. Journal of American College Health, 45, 243251.

Haberman, S., and Luffey, D. (1998). Weighing in college students' diet and exercise behaviors. Journal of American College Health, 46, 189-191.

Hertzler, A., Frary, R. (1989). Food behavior of college students. Adolescence, 24, 349-356.

Hiza, H., and Gerrior, S. (2002). Using the interactive healthy eating index to assess the quality of college students diets. Family Economics and Nutrition Review, 14, 3-11.

Hyson, D. (2002). The health benefits of fruits and vegetables. A scientific overview for health professionals. Produce for Better Health Foundation.

Jacobson, B. H., and DeBock, D. H. (2001). Comparison of body mass index by self-reported versus measured height and weight. Perceptual and Motor Skills, 92, 128-132. 
Lang, S. S. (2003). Junk food, snacks and all you can eat make 'freshman 15' a reality, with national obesity implications, Cornell nutritionists report. Cornell News. Retrieved March 15, 2004, from http://www.news.cornell.edu/releases/July03/freshman.15.weight.ssl.html

Lappalainen, R., Saba, A., Holm, L., Mykkanen, H., Gibney, M. J., Moles, A. (1997). Difficulties in trying to eat healthier: Descriptive analysis of perceived barriers for healthy eating. European Journal of Clinical Nutrition, 51(Suppl 2), S36-S40.

Leslie, E., Owen, N., Salmon, J., Bauman, A., Sallis, J. F., Lo, S. K. (1999). Insufficiently active Australian college students: Perceived personal, social, and environmental influences. Preventive Medicine, 28, 20-27.

Lopez-Azpiazu, I., Matinez-Gonzalez, M., Kearney, J., Gibney, M., Martinez, J. A. (1999). Perceived barriers of, and benefits to, healthy eating reported by a Spanish national sample. Public Health Nutrition, 2, 209-215.

Lowry, R., Galuska, D. A., Fulton, J. E., Weschler, H., Kann, L, Collins, J. L. (2000). Physical activity, food choice, and weight management goals and practices among US college students. American Journal of Preventive Medicine, 18, 18-27.

Melby, C. L., Femea, P. L., Sciacca, J. P. (1986). Reported dietary and exercise behaviors, beliefs and knowledge among university undergraduates Nutrition Research, 6, 799-808.

Myers, R., and Roth, D. (1997). Perceived benefits of and barriers to exercise and stage of exercise adoption in young adults. Health Psychology, 16, 277-283.

National Institute of Health. (1998). Executive summary of the clinical guidelines on the identification, evaluation, and treatment of overweight and obesity in adults. Retrieved March 15, 2004, from http://www.nhlbi.nih.gov/guidelines/obesity/ob_gdlns.htm

Nutrition Research Newsletter. (2002). Body dissatisfaction among college students. Retrieved March 15, 2004 from http://www.findarticles.com/cf_0/m0887/3_21/84209274/p1/article.jhtml

Pinto, B., Cherico, N., Szymanski, L., Marcus, B. (1998). Longitudinal change in college students' exercise participation. Journal of American College Health, 47, 23-27.

Pinto, B., and Marcus, B. (1995). A stages of change approach to understanding college students' physical activity. Journal of American College Health, 44, 27-31.

Rodriguez, J. (1999). Resident Freshmen Diet and Exercise Survey. University of North Florida. Retrieved January 15, 2002, from http://www.unf.edu/ jrodrigu/survey.htm

Tappe, M., Duda, J., Ehrnwald, P. (1989). Perceived barriers to exercise among adolescents. Journal of School Health, 59, 153-155.

Tufts Longitudinal Health Study (TLHS). (2000). More news. Retrieved March 15, 2004, from http://tlhs.tufts.edu/news/more_news.php

Van Duyn, M., and Pivonka, E. (2000). Overview of the health benefits of fruit and vegetable consumption for the dietetics professional: Selected literature. Journal of the American Dietetic Association, 100, 1511-1521.

Wallace, L., Buckworth, J., Kirby, T., Sherman, M. (2000). Characteristics of exercise behavior among college students: Applications of social cognitive theory to predicting stage of change. Preventive Medicine, 31, 494-505.

Wechsler, H., Lee, J. E., Kuo, M., Lee, H. (2000). College binge drinking in the 1990s: A continuing problem results of the Harvard School of Public Health 1999 college alcohol study. Journal of American College Health, 48, 199-210.

Wechsler, H., and Isaac, N. (1992) "Binge” drinkers at Massachusetts Colleges. Journal of the American Medical Association, 267, 2929-2931.

Young, L., and Nestle, M. (2002). The contribution of expanding portion sizes to the US obesity epidemic. American Journal of Public Health, 92, 246-249. 
Author Information

Kathryn Silliman, PhD, RD, Professor

Department of Biological Sciences

Program in Nutrition and Food Sciences

California State University

Chico CA 95929-0002

E-mail: ksilliman@csuchico.edu

Kathleen E. Rodas-Fortier, MS, RD

Department of Biological Sciences

Program in Nutrition and Food Sciences

California State University

Chico CA 95929-0002

E-mail: sweetse1970@msn.com

Michelle Neyman, PhD, RD, Assistant Professor

Department of Biological Sciences

Program in Nutrition and Food Sciences

California State University

Chico CA 95929-0002

E-mail: mneyman@csuchico.edu 